\title{
EFEKTIVITAS PROGRAM CORPORATE SOCIAL RESPONSIBILITY (CSR) BIDANG LINGKUNGAN HIDUP PADA HOTEL BINTANG LIMA DI KAWASAN PARIWISATA UBUD, KABUPATEN GIANYAR
}

\author{
Olivia Grace Brigitta Florencia ${ }^{1 *)}$, Made Sudiana Mahendra ${ }^{2)}$, I Wayan Arthana ${ }^{3)}$ \\ 1)Program Magister Ilmu Lingkungan Universitas Udayana \\ ${ }^{2)}$ Fakultas Pertanian Universitas Udayana \\ ${ }^{3)}$ Fakultas Kelautan dan Perikanan Universitas Udayana \\ *Email: addolivee@gmail.com
}

\begin{abstract}
The negative impact of tourism accommodation development, is environmental damage. Law of the Republic of Indonesia No. 10 of 2009 on Tourism Article 26, requires owner to be responsible through environmental maintenance.Law of the Republic of Indonesia No. 40 of 2007 on Limited Liability Companies Article 74, requires each company to implement Corporate Social Responsibility (CSR). The ministry of Environment itself summarizes the CSR on environment, such as Production Profit, Eco Office, Waste Management with 3R principle (Reduce, Reuse and Recycle), Conservation of Natural Resources and Energy, Renewable Energy, Climate Change Adaptation and Environmental Education. This research aimed to analyze the effectivity of CSR programs on environmental in fivestar hotels in Ubud Region, the factors that affect the program, and its development strategy. The research used descriptive quantitative method. The method of data collection using observation, interviews, and questionnaires. Data obtained was analyzed using descriptive qualitative method, complemented with IFAS (Internal Factor Analysis Summary), EFAS (External Factor Analysis Summary), and SWOT analysis. The result showed that implementation of CSR programs has not entirely been done effectively. From seven CSR programs, two programs have been categorized effective. Those two programs are Climate Change Adaptation and Environmental Education. However the program which has not run effectively is Production Profit, Eco Office, Waste Management with 3R principle (Reduce, Reuse and Recycle), Conservation of Natural Resources and Energy Renewable Energy. The main factor affecting CSR Program is organization, with score of 4.41. CSR implementation strategy, the manager continues the previous strategy that has been done. However, for the advancement of CSR programs is necessary needed revamping management, with concentration via vertical integration.
\end{abstract}

Keywords: 3R (Reduce, Reuse and Recycle); Environment; CSR Programs; SWOT

\section{PENDAHULUAN}

Tanggungjawab sosial muncul dan berkembang sejalan dengan adanya interelasi antara pihak perusahaan dan masyarakat, yang sangat ditentukan dari berbagai dampak yang timbul dari perkembangan dan peradaban masyarakat. Semakin tinggi tingkat peradaban suatu masyarakat, terutama akibat perkembangan ilmu pengetahuan sehingga meningkatkan rasa kesadaran dan perhatian terhadap lingkungan yang memunculkan tuntutan tanggung jawab perusahaan. Hal ini terjadi karena, peningkatan pengetahuan masyarakat berpengaruh terhadap peningkatan masa depan dan sustainabilitas pembangunan.

RajaGukGuk (2008) menyatakan bahwa, terjadinya diskusi pertama mengenai apakah suatu perusahaan mempunyai tanggung jawab sosial terjadi pada tahun 1930-an di Amerika Serikat. Saat itulah, pertama kali dalam sejarah istilah tanggung jawab sosial perusahaan atau Corporate Social Responsibility (CSR) lahir. Akan tetapi, Kartini (2009) dan Solihin (2009) setuju untuk merujuk pada pemikiran Brown (1953) dalam bukunya "Social Responsibility of the Businessman" menjadi awal kebangkitan CSR modern, sehingga Caroll (1999) menyebut Brown sebagai "Bapak CSR".

Konsep CSRatau pertanggungjawaban sosial di negara-negara maju seperti Eropa dan Amerika Serikat diberlakukan dan bersifat sukarela (voluntary) dan digunakan sebagai salah satu indikator penilaian kinerja sebuah perusahaan dengan dicantumkannya informasi CSR di catatan laporan keuangan perusahaan yang bersangkutan. CSR merupakan komitmen perusahaan atau dunia usaha untuk berkontribusi dalam pembangunan ekonomi yang berkelanjutan dengan menitikberatkan pada keseimbangan antara perhatian terhadap aspek ekonomi, sosial dan lingkungan. Terdapat tiga komponen penting dalam pelaksanaan CSR ini yaitu economic growth, environmental protection dan social equity. Elkington dalam Mardikanto (2004) mengemas CSRini kedalam tiga fokus yaitu 3P (Profit, Planet dan People), lebih lanjut Elkington berpendapat bahwa perusahaan yang baik tidak hanya memburu keuntungan 
ekonomi belaka (Profit), tetapi juga memiliki keperdulian terhadap kelestarian lingkungan (Planet) dan kesejahteraan masyarakat (People).

Di Indonesia secara yuridis pengaturan soal CSR secara eksplisit dalam hukum Indonesia dimulai ketika pemerintah memberlakukan UU No. 25 Tahun 2007 tentang penanaman modal, yang dalam Pasal 15 menyebut bahwa setiap penanam modal (perseorangan atau perusahaan, berbadan hukum ataupun bukan badan hukum) berkewajiban untuk menerapkan prinsip tata kelola perusahaan yang baik, melaksanakan tanggung jawab sosial perusahaan. Adanya perubahan Undang-Undang No.1 Tahun 1995 menjadi Undang-Undang No.40 Tahun 2007 tentang Perseroan Terbatas, telah membawa perubahan penting bagi dunia usaha di Indonesia. CSRdi Indonesia dinamakan dengan istilah Tanggung Jawab Sosial Perusahaan (TJSP) atau Tanggung Jawab Sosial dan Lingkungan Perseroan (TJSLP). Selama kurun waktu empat tahun terakhir hampir seluruh perusahaan dari berbagai sektor bisnis di Indonesia sebagian besar mengklaim bahwa perusahaan mereka telah melaksanakan kewajiban sosialnya terhadap lingkungan sekitar perusahaan. Oleh karena itu, sebagian besar perusahaan tersebut melakukan pengungkapan CSRsebagai motivasi untuk meningkatkan kepercayaaan publik terhadap pencapaian usaha perbaikan terhadap lingkungan sekitar perusahaan.

Berkembangnya isu CSR baik ditingkat global maupun di Indonesia juga dipicu oleh banyak kasus yang terjadi di dalam komunitas bisnis. Sebagai contoh,kasus Lumpur Panas di Sidorajo, Jawa Timur, yang disebabkan oleh PT. Lapindo Brantas telah mengakibatkan ratusan tempat tinggal penduduk terendam. Debit semburan lumpur yang berasal dari perut bumi telah mencapai $156.000 \mathrm{~m}^{3}$ pada bulan keenam terhitung dari awal terjadinya semburan, hingga membutuhkan 10.000 armada truk per hari untuk mengangkat lumpur tersebut (Wibisono, 2007). Terjadinya kasus-kasus yang berkaitan dengan lingkungan dan pekerja seperti yang telah disebutkan di atas, semakin memperjelas kebutuhan pelaksanaan dan pengungkapan CSR oleh perusahaan. Sehingga tidak hanya perusahaan yang bergerak dibidang industri yang wajib melaksanakan program CSR, namun juga bagi perusahaan yang bergerak di bidang pariwisata.

Di Bali, perkembangan pesat pada sektor jasa pariwisata didukung dengan pembangunan berbagai akomodasi pariwisata seperti hotel, vila, pondok wisata dan restoran. Berdasarkan laporan dari Dinas Pariwisata Provinsi Bali (2013) bahwa pembangunan kamar untuk pondok wisata, hotel melati dan hotel berbintang telah mencapai 2.577 dengan jumlah 44.318 kamar.Akibatdarikondisitersebut, Bali menghadapi alih fungsi lahan yang cukupbesar.
Keberadaan akomodasi pariwisata tentu dapat menimbulkan dampak positif bagi masyarakat setempat seperti menciptakan lapangan pekerjaan, menambah wawasan masyarakat tentang bagaimana karakteristik bangsa-bangsa dari berbagai dunia, serta mendorong meningkatnya pendidikan dan keterampilan masyarakat sekitar. Terlepas dari hal positif diatas dengan adanya pembangunan berbagai akomodasi pariwisata juga terdapat dampak negatif yang ditimbulkan seperti perubahan sistem nilai dalam moral, etika, kepercayaan, dan tata pergaulan dalam masyarakat, dan dampak yang terpenting terjadinya kerusakan lingkungan seperti pencemaran air, tanah dan udara akibat dari kegiatan operasional. Pencemaran lingkungan menjadi masalah serius yang harus mendapatkan perhatian khusus dari pemilik usaha atau kegiatan, masyarakat, dan instansi yang terkait.

Pasal 74 UU No. 40 tahun 2007 tentang Perseroan Terbatas mewajibkan setiap perusahaan utntuk melakukan CSR, namun karena dalam UUPT belum memberikan kriteria yang jelas mengenai CSR dibidang jasa perhotelan maka secara umum hotel-hotel menafsirkan belum ada kewajiban untuk melaksanakan CSR. Dalam UU No. 10 tahun 2009 tentang Kepariwisataan pasal 26, mewajibkan setiap pengusaha pariwisata untuk bertanggung jawab terhadap memelihara lingkungan yang sehat, bersih, dan asri serta memelihara kelestarian lingkungan alam dan budaya. Sebagai upaya mewujudkan harmonisasi antara perusahaan dengan lingkungan, sejak tahun 2011 KLH telah merangkum CSR bidang lingkungan yang dapat menjadi komitmen dari dunia usaha untuk peduli terhadap lingkungan yang terdiri dari Produksi Bersih, Kantor Ramah Lingkungan (Eco Office), Pengelolaan Sampah dengan Prinsip 3R (Reduce, Reuse and Recycle), Konservasi Sumberdaya Alam dan Energi, Energi Terbarukan(Renewable Energy), Adaptasi Perubahan Iklim dan Pendidikan Lingkungan Hidup (PLH). Berdasarkan hal tersebut, penelitian ini diharapkan mampu memberikan gambaran mengenai efektivitas program CSR bidang lingkungan hidup pada hotel bintang lima dan faktor yang mempengaruhi efektivitas pelaksanaan program CSR serta strategi pelaksanaan program CSR bidang lingkungan hidup.

\section{METODOLOGI}

Pendekatan yang digunakan dalam penelitian ini adalah metode deskriptif kuantitatif. Secara detail penelitian ini akan memaparkan keadaan dan kondisi yang berhubungan dengan program CSR bidang lingkungan. Lokasi penelitian ini dilakukan di Kawasan Pariwisata Ubud, Kabupaten Gianyar. 
Jumlah populasi atau sampel dalam penelitian ini adalah seluruh hotel bintang lima di Kawasan Pariwisata Ubud yang berjumlah empat hotel bintang lima yang terletak di pada Desa Sayan, Kedewatan, Petulu dan Peliatan. Selanjutnya, yang akan menjadi responden dalam penelitian ini adalah manajemen hotel dan tenaga kerja serta masyarakat di Kawasan Pariwisata Ubud yang menerima manfaat dari program CSR, yaitu Kepala Desa, Kepala Banjar, Kelian Dinas, Kelian Adat dan penduduk sekitar, yang berjumlah sepuluh untuk masing-masing hotel.

Analisis tujuan penelitian yang pertama yaitu untuk melihat gambaran keefektivan serta faktor yang mempengaruhi program CSR bidang lingkungan hidup dengan membuat rentang skala (Wiratna, 2012) :

$$
\mathrm{R}=\mathrm{Xt}-\mathrm{Xr}
$$

Dimana :

$\mathrm{R}=$ Interval
$\mathrm{Xt}=$ Nilai Maksimal
$\mathrm{Xr}=$ Nilai Minimum

$$
\text { Panjang Interval }=\frac{R}{\text { Jenjang }}
$$

Analisis tujuan penelitian kedua yaitu untuk mendapatkan faktor kekuatan dan faktor kelemahan yang akan diantisipasi. Untuk mengevaluasi faktor tersebut digunakan matriks IFAS (Internal Factor Analysis Summary). Kemudian, analisis eksternal dilakukan untuk mengembangkan faktor peluang yang kira-kiranya dapat dimanfaatkan dan faktor ancaman yang perlu dihindari. Hasil analisis eksternal dilanjutkan untuk mengevaluasi guna mengetahui apakah strategi yang dipakai selama ini memberikan respon terhadap peluang dan ancaman yang ada dengan menggunakan matriks EFAS (External Factors Analisys Summary). Selanjutnya matriks IFAS EFAS akan digunakan untuk dapat memposisikan strategi yang akan digunakan oleh perusahaan. Matriks IFAS EFAS terdiri dari dua sumbu yakni skor yang didapat dari tabel IFAS pada sumbu X, serta skor yang didapat dari tabel EFAS digunakan pada sumbu Y.

Analisis tujuan penelitian ketiga yaitu untuk merumuskan sebuah strategi perusahaan secara sistematis melalui analisis SWOT. Analisis SWOT digunakan untuk menciptakan sebuah strategi pelaksanaan program CSR bidang lingkungan hidup, sehingga dapat diterapkan pada seluruh pelaku sektor pariwisata, dalam hal ini adalah hotel bintang lima, baik yang telah memiliki dan melaksanakan program CSR ataupun yang belum pernah melaksanakan program CSR.

\section{HASIL DAN PEMBAHASAN}

\subsection{Efektivitas Program CSR Bidang Ling- kungan Hidup}

Implementasi prinsip produksi bersih merupakan salah satu program CSR yang berkesinambungan dan dilakukan oleh perusahaan dalam rangka penghematan energi dan sumber daya alam. Program ini bertujuan untuk meningkatkan efisiensi dan mencapai keunggulan lingkungan yang lebih baik daripada standar pengelolaan lingkungan yang diwajibkan oleh regulasi Kementerian Lingkungan Hidup.Penerapan program CSR bidang produksi bersih yang telah dilakukan oleh pihak hotel yakni dengan pemanfaatan air yang dapat dijadikan sumber air bersih dan pendistribusian air bersih bagi masyarakat. Namun, tidak semua hotel menerapkan program CSR produksi bersih dengan melibatkan masyarakat seperti hotel A dan hotel B yang hanya melaksanakan program produksi bersih di lingkungan internal perusahaan, sehingga kegiatan yang dilakukan kedua hotel ini tidak dapat dikategorikan sebagai program CSR, hingga pada hasil akhirperolehan skor untuk program CSR bidang produksi bersih hanya mencapai 2,03 dengan kategori tidak efektif. Pelibatan dan peran aktif masyarakat dalam pelaksanaan Program CSR merupakan kunci utama keberhasilan. Hal ini sejalan dengan instruksi yang dikeluarkan oleh Permen Negara Lingkungan Hidup Nomor 31 Tahun 2009 tentang Pembinaan dan Pengawasan Penerapan Sistem Manajemen Lingkungan, Ekolabel, Produksi Bersih, dan Teknologi Berwawasan Lingkungan di Daerah yang menyatakan bahwa produksi bersih merupakan strategi pengelolaan yang bersifat preventif, terpadu dan diterapkan secara berkesinambungan.Program ini bertujuan untuk meningkatkan efisiensi penggunaan bahan baku atau sumberdaya alam dan mencegah pencemaran lingkungan serta mengurangi terjadinya limbah produksi.

Program CSR bidang kantor ramah lingkungan(Eco Office)tidakberjalanefektif denganskor akhir 0. Sebagaimana hotel A, B, C, dan D tidak melibatkan partisipasi masyarakat dalam pelaksanaan program ini, sehingga kegiatan ini tidak dapat dikategorikan sebagai program CSR. Saat ini pelaksanaan kegiatan program masih sebatas internal perusahaan, seperti penggunaan bahan baku lokal, penghematan listrik, penghematan kertas, pemakaian alat listrik hemat daya, serta pelaksanaan kegiatan earth hour. Hotel seyogyanya mempunyai tanggungjawab untuk mengembangkan lingkungan sekitarnya melalui program-program sosial yang komprehensif dan berkesinambungan. Menurut Lesmana (2006), program CSRbaru dapat menjadi berkelanjutan apabila, program yang dirancang oleh suatu perusahaan benar-benar 
merupakan komitmen bersama dari segenap unsur yang ada di dalam perusahaan itu sendiri. Tentunya tanpa adanya komitmen dan dukungan dengan penuh antusias dari karyawan akan menjadikan program-program tersebut bagaikan program penebusan dosa dari pemegang saham belaka.

Upaya untuk menurunkan dampak lingkungan dilakukan salah satunya dengan cara mengurangi sampah. Dalam program CSR pengelolaan sampah dengan prinsip 3R (Reduce, Reuse and Recycle), hasil yang didapatkan masih rendah dengan skor 1,06. Tidak semua hotel menerapkan program ini dengan melibatkan partisipasi masyarakat dikarenakan adanya kerjasama dengan pihak ketiga dalam pengelolaan sampah. Namun hotel B mempunyai program terkait edukasi kepada masyarakat dimulai dari pemilahan sampah plastik dari sumber dilanjutkan dengan prinsip reuse dan recycle dengan memanfaatkan kembali sampah sehingga memiliki nilai ekonomis.Sesuai dengan Undang-Undang No. 18 tahun 2008 tentang Pengelolaan Sampah, pengelolaan sampah adalah kegiatan yang sistematis, menyeluruh, dan berkesinambungan yang meliputi pengurangan dan penanganan sampah. Keberadaan sampah jika tidak dikelola secara baik dan benar akan menimbulkan gangguan dan dampak terhadap lingkungan. Keberhasilan program tentunya didukung dengan upaya perusahaan untuk melakukan edukasi dan sosialisasi secara komprehensif.

Program CSR konservasi sumber daya alam dan energi berjalan tidak efektif dengan skor 2,12 . Adapun program yang dilakukan pleh pihak hotel berupa memperhatikan kelestarian hayati di lingkungan hotel, penanaman pohon dan penghijauan baik di dalam maupun di luar kawasan hotel, mengalokasikan dana untuk pemeliharaan mangrove dan pelestarian satwa langka. Padadasarnya program-program CSR dapat disinergikan dan mendapatkan dukungan dari masyarakat secara langsung. Pada dasarnya program-program CSR dapat disinergikan dan mendapatkan dukungan dari masyarakat secara langsung. Program Konservasi Sumberdaya Alam dan Energi menjadi salah satu contoh adanya partisipasi aktif masyarakat dan masyarakat secara tidak langsung juga mendapatkan manfaat dengan semakin membaiknya kondisi lingkungan. Program Konservasi Sumberdaya Alam dan Energi ternyata memiliki potensi meningkatkan kesejahteraan masyarakat sekitar, dan perlu didukung oleh semua pihak. Hal ini sejalan dengan pendapat Rachman (2009) bahwa pembangunan konservasi harus dilaksanakan bersama pula, yaitu Pemerintah, masyarakat, dunia usaha/swasta dan perguruan tinggi, serta lembaga swadaya masyarakat, dll. Setiap institusi memiliki fungsi yang sesuai dengan posisinya.
Program CSR energi terbarukan (Renewable Energy) berjalan tidak efektif dengan skor 2,09. Hasil penelitian menunjukkan bahwa keseluruhan hotel bintang lima di Kawasan Pariwisata Ubud belum menerapkan konsep energi terbarukan secara terintegrasi dan berkesinambungan. Berkenaan dengan konsep energi terbarukan, pada dasarnya kegiatan ini dapat mengurangi proses eksplorasi dan eksploitasi sumber energi fossil yang jumlahnya saat ini semakin terbatas. Kegiatan ini memiliki beberapa kendala, diantaranya sulitnya mendapatkan pasokan energi dengan biaya yang terjangkau. Hal ini disebabkan oleh beberapa kendala yaitu tingginya biaya operasional dan terbatasnya SDM untuk melakukan pemeliharaan dan organisasi manajemen operasional.

Diketahui bahwa program CSR adaptasi perubahan iklim telah berjalan efektif, dengan skor 3,99. Hasil penelitian menunjukkan bahwa kegiatankegiatan yang dilakukan oleh hotel bintang lima sudah merupakan kegiatan adaptasi terhadap perubahan iklim. Namun kegiatan tersebut perlu diperkuat dengan menyertakan pertimbangan mengenai dampak perubahan iklim. Oleh karena itu, program CSR bidang adaptasi perubahan iklim harus mampu menjaga keutuhan fungsi dan tatanan lingkungan, sehingga sumber daya alam yang ada dapat senantiasa tersedia guna mendukung kegiatan pembangunan baik untuk masa sekarang maupun masa yang akan datang.

Sumber daya manusia memegang peranan penting dalam mendorong perbaikan lingkungan, salah satunya yakni melalui pelaksanaan program CSR pendidikan lingkungan hidup. Di Kawasan Pariwisata Ubud, implementasi program yang dijalankan oleh pihak hotel berjalan efektif, dengan skor 4,09. Pelaksanaan program CSR bidang pendidikan lingkungan hidup bergerak pada aspek pengembangan masyarakat seperti program pengenalan lingkungan hidup untuk tingkat anakanak sekolah dasar, pemilahan sampah, dukungan sekolah berbasis peduli lingkungan, serta memberikan bantuan guna pengembangan pendidikan. Pendidikan lingkungan hidup merupakan salah satu pilihan program CSR yang sering mendapatkan perhatian perusahaan.Konsistensi dan kerja sama dengan para pihak terkait agar program dapat terlaksana secara optimal dan keberlanjutan, juga menjadi salah satu keberhasilan dari pelaksanaan program yang dilakukan secara bertahap. Arah implementasi CSR bidang pendidikan makin terasa diwujudkan oleh berbagai perusahaan saat ini.

\subsection{Faktor yang Mempengaruhi Efektivitas Program CSR}

Hasil penelitian menunjukkan bahwa seluruh faktor penerima bantuan program CSR berpengaruh terhadap efektivitas program CSR bidang lingkungan 
hidup dengan total skor 3.71. Faktor organisasi sangat berpengaruh pada program CSR dengan skor 4.41. Faktor prioritas kebutuhan cukup berpengaruh pada efektivitas program CSR dengan skor 3.35.

Berdasarkan hasil perhitungan terhadap faktorfaktor yang mempengaruhi program CSR diperoleh nilai yang terbesar diberikan oleh faktor organisasi, yaitu sebesar 4.41 dengan penilaian sangat berpengaruh. Dari hasil sebaran jawaban responden untuk pengaruh organisasi yang berpengaruh terhadap efektivitas pelaksanaan program CSR bidang lingkungan hidup terdiri atas kinerja karyawan hotel bintang lima dalam melakukan program CSR bidang lingkungan hidup, informasi dari perusahaan ke masyarakat, sosialisasi dari perusahaan ke masyarakat, dan konsistensi perusahaan dalam program CSR terhadap masyarakat.

\subsection{Analisis IFAS dan EFAS}

Nilai total penjumlahan perkalian antara bobot dan rating untuk faktor internal dan eksternal digunakan untuk memposisikan strategi umum yang digunakan dalam pelaksanaan program CSR bidang lingkungan hidup. Hasil penjumlahan perkalian antara bobot dan rating untuk faktor internal (IFAS) menghasilkan nilai 3.128, sedangkan hasil penjumlahan perkalian antara bobot dan rating untuk faktor eksternal (EFAS) menghasilkan nilai 2.914. Hal tersebut memposisikan strategi umum yang digunakan adalah strategi pada sel I dengan strategi pertumbuhan melalui integrasi vertikal.

Terdapat dua strategi umum yang dapat dilakukan dalam pelaksanaan program CSR bidang lingkungan hidup pada hotel bintang lima di Kawasan Pariwisata Ubud, yaitu:

1. Strategi pertumbuhan melalui integrasi vertikal, yakni dilakukan dengan identifikasi kebutuhan SDM untuk menerapkan CSR bidang lingkungan, penetapan secara formal struktur organisasi yang mengelola CSR bidang

Tabel 1. Matrik IFAS EFAS

Strategi Umum Peningkatan Efektivitas Program CSR Bidang Lingkungan Hidup pada Hotel Bintang Lima di Kawasan Pariwisata Ubud

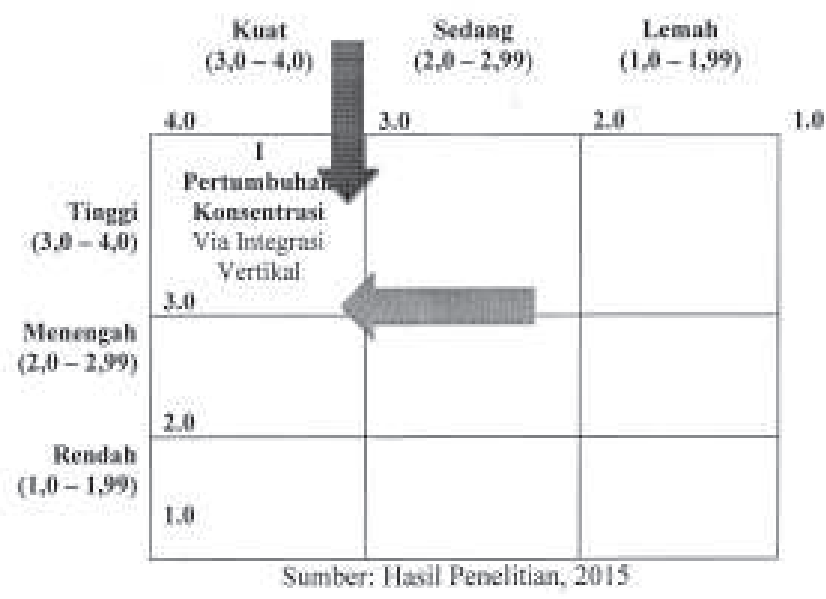

lingkungan, penetapan peran, wewenang dan kewajiban pengelolaan CSR bidang lingkungan, identifikasi kebutuhan kompetensi pengelolaan CSR bidang lingkungan, serta upaya pemenuhan kebutuhan kompetensi pengelolaan CSR bidang lingkungan. Serta diperlukan juga strategi via integrasi horizontal dengan cara melakukan peningkatan intensitas komunikasi pada stakeholder utama untuk mengantisipasi berbagai kendala yang mungkin terjadi sekaligus memonitoring dan evaluasi terhadap pelaksanaan program CSR bidang lingkungan.

2. Strategi stabilitas. Strategi ini digunakan pada pelaksanaan program CSR bidang lingkungan hidup, yaitu perusahaan tetap mempertahankan dan meningkatkan kepedulian pada lingkungan dan masyarakat agar tercipta lingkungan yang bersih dan kehidupan masyarakat yang lebih baik, perusahaan mengupayakan program CSR bidang lingkungan dapat membangun kemandirian masyarakat dan sustainable (berkelanjutan), seluruh pelaksana program CSR harus merancang dengan baik program CSR tersebut agar tepat sasaran dan masyarakat mendapat manfaat yang optimal.

\subsection{Analisis SWOT}

Analisis SWOT didasarkan pada logika untuk memaksimalkan kekuatan (strength) dan peluang (opportunities), namun secara bersamaan dapat meminimalkan kelemahan (weakness) dan ancaman (threats). Dalam mewujudkan pelaksanaan program CSR bidang lingkungan hidup terdapat empat strategi yang dapat digunakan untuk oleh hotel bintang lima di Kawasan Pariwisata Ubud, yakni sebagai berikut:

\section{A. Strategi Strenght-Opportunities (SO)}

Strategi SO adalah strategi yang meningkatkan indikator kekuatan yang dimiliki hotel bintang lima dengan cara memanfaatkan indikator peluangpeluang yang ada dalam pelaksanaan program CSR bidang lingkungan hidup yaitu:

1. Meningkatkan kesadaran para pengelola hotel untuk lebih memfokuskan program CSR berbasis lingkungan hidup.

2. Meminta dukungan pemerintah pusat melalui Kementerian Pariwisata dan Budaya untuk menumbuhkan gerakan cinta lingkungan hidup.

3. Melakukan strategi sosialiasasi program CSR yang terintegrasi antara berbagai pihak yang berkompeten melalui media internet.

4. Memberi motivasi kepada para penyelenggara program CSR untuk lebih serius dan fokus dalam memberikan pelayanan kepada masyarakat.

B. Strategi Strenght-Threats (TS)

Strategi ST adalah strategi yang bertujuan meningkatkan kekuatan yang dimiliki untuk 
menimimalkan ancaman-ancaman yang muncul dalam pelaksanaan program CSR bidang lingkungan hidup yaitu:

1. Meningkatkan kegiatan sosialiasi program CSR kepada masyarakat agar tertarik untuk berpartisipasi aktif dalam menjaga kelestarian lingkungan hidup.

2. Meningkatkan kesadaran kepada para pengelola jasa pariwisata untuk turut berpartisipasi aktif dalam program lingkungan hidup.

3. Meningkatkan dan memperbaiki sistematika penyelenggaraan program CSR di setiap hotel.

\section{Strategi Weakness-Opportunities (WO)}

Strategi WO adalah strategi yang bertujuan untuk meminimalkan kelemahan yang ada dengan dengan cara memanfaatkan peluang-peluang yang dimiliki dalam pelaksanaan program CSR bidang lingkungan hidup yaitu:

1. Mempertegas kebijakan Program CSR secara jelas, kongkret serta tertulis sebagai untuk standar operasional CSR.

2. Mengubah paradigma top manajemen hotel bahwa CSR bukan upaya meredam protes dan solusi konflik.

3. Melibatkan masyarakat sebagai bagian dari tujuan program CSR.

4. Meningkatkan keterampilan petugas CSR dalam perencanaan dan evaluasi proyek.

5. Melibatkan partisipasi komunitas untuk pelaksanaanprogram CSR, sehingga bermanfaat jangka panjang.

6. Melakukan proses evaluasi program CSR yang sistematis.

7. Menyiapkan memiliki budget yang memadai untuk melaksanakan program CSR bidang energi terbarukan.

8. Meningkatkan kesadaran dan partisipasi masyarakat dalam kegiatan CSR.

\section{Strategi Weakness-Threats (WT)}

Strategi WT adalah strategi yang digunakan untuk mengurangi kelemahan yang ada sehingga dapat memperkecil atau mengilangkan ancaman yang muncul dalam pelaksanaan program CSR bidang lingkungan hidup yaitu:

1. Meningkatkan pemahaman dan minat masyarakat untuk menjaga kebersihan dan kelestarian lingkungan.

2. Meningkatkan kesadaran para pengelola jasa pariwisata untuk memiliki tanggung jawab sosial kepada masyarakat khususnya di bidang lingkungan hidup.

3. Memperketat izin pendirian bangunan di kawasan konservasi.

\section{SIMPULAN DAN SARAN}

\subsection{Simpulan}

1. Program CSR bidang lingkungan hidup pada hotel bintang lima di Kawasan Pariwisata Ubud belum berjalan efektif. Dari ketujuh program CSR Lingkungan Hidup yang telah diterapkan, hanya dua program telah berjalan efektif yakni Adaptasi Perubahan Iklim dan Pendidikan Lingkungan Hidup (PLH), sedangkan lima program lainnya belum berjalan dengan efektif adalah Produksi Bersih, Kantor Ramah Lingkungan (Eco Office), Pengelolaan Sampah dengan Prinsip 3R (Reduce, Reuse and Recycle), Konservasi Sumber Daya Alam dan Energi, serta Program Energi Terbarukan (Renewable Energy).

2. Faktor-faktor yang mempengaruhi program CSR diperoleh nilai yang terbesar diberikan oleh faktor organisasi yaitu sebesar 4,41 dengan penilaian sangat berpengaruh. Untuk setiap faktor yang dibentuk oleh atribut-atribut pengaruh program CSR, faktor yang memiliki pengaruh signifikan terhadap efektivitas program CSR adalah faktor organisasi.

3. Strategi umum yang dapat dilakukan dalam pelaksanaan program CSR bidang lingkungan hidup pada hotel bintang lima di Kawasan Pariwisata Ubud, yaitu strategi pertumbuhan melalui integrasi vertikal dengan nilai perolehan faktor internal (IFAS) sebesar 3.128. Hal ini dapat dilakukan dengan melakukan identifikasi kebutuhan SDM menerapkan CSR bidang lingkungan hidup secara formal dan strategi via integrasi horizontal dengan meningkatkan intensitas komunikasi dengan stakeholder utama, serta strategi stabilitas yang digunakan pada pelaksanaan program CSR.

\subsection{Saran}

1. Kepada perusahaan pengelola program CSR bidang lingkungan hidup di Kawasan Pariwisata Ubud disarankan untuk merekrut karyawan yang khusus menangani masalah CSR ataupun bekerja sama dengan pihak luar untuk membantu memberdayakan masyarakat penerima bantuan tadi sehingga program CSR bidang lingkungan hidup di Kawasan Pariwisata Ubud bisa sampai tahap corporate citizenship.

2. Strategi yang perlu dilaksanakan untuk mengefektifkan program CSR bidang lingkungan hidup di Kawasan Pariwisata Ubud adalah melakukan sosialisasi mengenai kelembagaan CSR yang intensif kepada perusahaan dan forum perusahaan yang belum menjadi anggota CSR. 


\section{DAFTAR PUSTAKA}

Brown, H.R. 1953. Social Responsibility of the businessman. New York, Harper \& Row.

Carrol, A.B. 1999. Corporate Social Responsibility; Evolution of Definition Construct. Business and Society. University of Georgia, Sage Publicatio. Vol: 38, No: 3. p. 268-293.

Kartini, D. 2009. Corporate Social Responsibility (Transformasi Konsep Sustainability Management dan Implementasi di Indonesia). Bandung, RefikaAditama.

Lesmana, T. 2006. Program Corporate Social Responsibility yang Berkelanjutan.Majalah Lensa ed 1 November 2006. (http://business environment.wordpress.com/2007/03/01/ program-corporate-socialresponsibilityyangberkelanjutan).

Mardikanto, T. 2004. Corporate Social Responsibility (Tanggung Jawab Sosial Koorporasi). Bandung, Alfabeta.

Peraturan Menteri Negara Lingkungan Hidup No. 31 Tahun 2009, tentang Pembinaan dan Pengawasan Penerapan Sistem Manajemen Lingkungan, Ekolabel, Produksi Bersih, dan Teknologi Berwawasan Lingkungan di Daerah.
Rahman, R. 2009. Corporate Social Responsibility Antara Teori dan Kenyataan. Yogyakarta, Media Pressindo.

RajaGukGuk, E. 2008. Konsep dan Perkembangan Pemikiran tentang Tanggung Jawab Sosial Perusahaan. Workshop Tanggung Jawab Sosial Perusahaan Pushum UII Yogyakarta bekerjasama dengan Norsk Center for Mennesekerettigheter Norwegian Center for Human Rights. Yogyakarta.

Solihin, I. 2009. Corporate Social Responsibility From Charity to Sustainabilility. Jakarta, Salemba Empat.

Undang-Undang No.18 Tahun 2008, tentang Pengelolaan Sampah.

Undang-Undang No. 25 Tahun 2007, tentang Penanaman Modal.

Undang-Undang No.40 Tahun 2007, tentang Perseroan Terbatas.

Wibisono. 2007. Membedah Konsep dan Aplikasi Corporate Social Responsibility. Surabaya, Media Grapka.

Wiratna, S.V. 2012. Statistika untuk Penelitian. Yogyakarta, Graha Ilmu. 